\title{
Job Loss, Unemployment, Work Stress, Job Satisfaction, and the Persistence of Posttraumatic Stress Disorder One Year After the September 11 Attacks
}

\author{
Arijit Nandi, MPH \\ Sandro Galea, MD, DrPH \\ Melissa Tracy, BA \\ Jennifer Ahern, MPH \\ Heidi Resnick, PhD \\ Robyn Gershon, MHS, DrPH \\ David Vlahov, PhD
}

The influence of unemployment and adverse work conditions on the course of psychopathology after a mass disaster is unclear. We recruited a representative sample of adults living in the New York City metropolitan area six months after the September 11 attacks and completed follow-up interviews on $71 \%$ of the baseline sample six months later $(\mathrm{N}=1939)$. At follow-up, posttraumatic stress disorder (PTSD) persisted in $42.7 \%$ of the 149 cases with PTSD at baseline. In multivariable models, unemployment at any time since baseline predicted PTSD persistence in the entire cohort $(\mathrm{P}=0.02)$ and among persons employed at follow-up $(\mathrm{P}=0.02)$. High levels of perceived work stress predicted PTSD persistence among persons employed at follow-up $(\mathrm{P}=0.02)$. Persons unemployed in the aftermath of a disaster may be at risk for poor mental health in the long-term. (J Occup Environ Med. 2004;46:1057-1064)

\footnotetext{
From the Center for Urban Epidemiologic Studies, New York Academy of Medicine, New York, NY (Mr. Nandi, Dr. Galea, Ms. Tracy, Ms. Ahern, and Dr. Vlahov); Columbia University Mailman School of Public Health, New York, NY (Drs. Galea, Gershon, and Vlahov); and the National Crime Victims' Research and Treatment Center, Medical University of South Carolina, Charleston, South Carolina (Dr. Resnick).

Address correspondence to: Sandro Galea, MD, DrPH, Center for Urban Epidemiologic Studies, Room 556, The New York Academy of Medicine, 1216 5th Avenue, New York, NY 10029-5283; E-mail: sgalea@nyam.org.

Copyright $(C)$ by American College of Occupational and Environmental Medicine

DOI: 10.1097/01.jom.0000141663.22902.0a
}

he September 11 terrorist attacks caused enormous damage to the New York City (NYC) regional economy, exacerbating the mild recession documented in NYC in the first quarter of $2001 .^{1}$ In the last three months of 2001, every industry in NYC experienced job loss, with the exception of the construction industry. ${ }^{2}$ Concomitantly, unemployment rates in the NYC region increased from $6.5 \%$ in September 2001 to $7.6 \%$ in September $2002,{ }^{3}$ and by July of 2002, an estimated 146,100 jobs in NYC were lost directly or indirectly as the result of the September 11 attacks. ${ }^{1}$

In addition to contributing to increased unemployment, the September 11 attacks altered the work environment for those who remained employed during the recession. Several polls documented the changes that transpired in the workplace after September 11. A general population survey of New Yorkers found that almost one third of persons who completed in-person interviews three to six months after the September 11 attacks had their employment circumstances negatively affected in some way by the attacks, primarily by losing a job, losing time from work, or experiencing reduced hours or responsibilities at work. ${ }^{4}$ An excess of 75,000 NYC workers worked fewer hours and accepted commensurate reductions in wages in the fourth quarter of 2001 to avoid layoffs. ${ }^{5}$ Additionally, a New York Times/CBS telephone survey re- 
ported that more than one third of adults experienced longer commutes to work in the weeks after the attacks, and almost one sixth reported similar problems one year after the attacks. ${ }^{6}$ Together, these reports suggest that the September 11 attacks were associated both with considerable job losses and with compromised and more stressful work conditions for a substantial proportion of NYC residents.

The September 11 terrorist attacks also resulted in substantial psychologic morbidity for residents of NYC. A study assessing the prevalence of posttraumatic stress disorder (PTSD) and depression in the first two months after the attacks found that the prevalence of these disorders was at least two to three times higher than might be expected at baseline. ${ }^{7}$ Further research documented the rapid resolution of many PTSD symptoms in the months after September $11^{8}$; however, a substantial proportion of probable PTSD cases in this study persisted six months after September 11, with job loss as a result of the September 11 attacks associated with the persistence of probable PTSD in multivariable models controlling for other event experiences. $^{8}$

Economic decline in general, and unemployment in particular, have been shown to be associated with adverse mental health. For instance, recessions are negatively associated with mental health outcomes. ${ }^{9,10}$ In a general population survey conducted in Sweden, periods of recession were related to increased levels of psychologic distress among employed and unemployed persons. ${ }^{9}$ Under the demand-control model, conceptualized by Karasek and Theorell, negative psychosocial changes in the work environment are hypothesized to adversely affect the mental health of workers. ${ }^{11}$ Among victims of trauma, research suggests that both unemployment and stressful work conditions experienced after exposure to traumatic events have longterm, negative effects on mental health. ${ }^{12-18}$ However, very little work has explored the influence of unemployment and adverse work conditions on the recovery from psychologic morbidity associated with a mass disaster. One study found that reemployment difficulties were significantly associated with higher posttraumatic symptom scores among survivors of an oil platform disaster. ${ }^{19}$

We were interested in assessing the role of job loss and work conditions on the persistence of PTSD in the aftermath of a disaster. We hypothesized that job loss, unemployment, higher levels of perceived work stress, and reduced job satisfaction would predict the persistence of probable PTSD 12 months after the September 11 attacks.

\section{Methods}

\section{Participants}

We conducted a random-digit-dial household survey to recruit baseline respondents approximately six months after the September 11 attacks (March 25-June 25, 2002). The sampling frame consisted of all adults (18 years of age and older) in the NYC metropolitan area, including the following contiguous geographic areas: New York City and Nassau, Westchester, Suffolk, and Rockland counties in New York State; Hudson, Essex, Bergen, Passaic, Union, Middlesex, Monmouth, Morris, and Somerset counties in New Jersey; and Lower Fairfield county in Connecticut. Interviews were conducted in English, Spanish, Mandarin, and Cantonese by trained interviewers using translated and back-translated questionnaires and a computer-assisted telephone interview system. Households were screened for eligibility by location. If eligible, an adult in each household was randomly selected by choosing the adult whose birthday was closest to the interview date. Up to 10 attempts were made to conduct the interview. The cooperation rate for the baseline survey was $56 \%$ (coop- eration rate $=[$ completed interviews + quota-outs + screen-outs]/[complete interviews + quota-outs + screen-outs + refusals + premature terminations]) and the overall response rate was $34 \%$ (response rate $=[$ completed interviews + partial interviews]/[all eligible residential telephone numbers + telephone numbers of unknown eligibility]). Further details on sample selection are provided elsewhere. ${ }^{8}$

Contact information was obtained for respondents, their key family members, and other important contacts. Six months later, we conducted follow-up interviews (September 25, 2002-January 31, 2003) and were successful in contacting and completing interviews on 1939 (71\%) of all baseline respondents. The mean interview time for both surveys was approximately 35 minutes. The Institutional Review Board at the New York Academy of Medicine approved the study and all study subjects provided verbal consent at the time of the interview.

\section{Measures}

At baseline, we asked if the respondent had lost a job as a result of September 11. Respondents reported their household income at baseline and follow-up $(<\$ 20,000, \$ 20,000$ $29,999, \$ 30,000-39,999, \$ 40,000$ $49,999, \$ 50,000-74,999, \$ 75,000$ $99,999$, or $\geq \$ 100,000)$ and responses were compared to determine changes in income over the study period. At follow-up, we asked if the respondent had been unemployed for any period of time since baseline. Respondents currently employed at follow-up were asked to rate the level of their work stress (eg, being overwhelmed at work or overworked) using a 5-point scale with 1 representing the lowest level of stress. For the analysis, we categorized work stress responses of 1,2 , or 3 as "low" and responses of 4 or 5 as "high." We also asked currently employed respondents if their job satisfaction was "better now than before September 11, worse now, or 
TABLE 1

Demographics of the New York City Metropolitan Area Cohort and Comparison to Census 2000 Data

\begin{tabular}{lrccc} 
& No. & Weighted (\%) & Census 2000 (\%) & $\boldsymbol{P}$ value \\
\hline Total & 1939 & & & \\
Age & & & & \\
18-24 & 164 & 13.7 & 11.7 & 0.66 \\
$25-34$ & 389 & 23.9 & 20.4 & \\
$35-44$ & 424 & 20.6 & 21.9 & \\
$45-54$ & 398 & 19.0 & 17.7 & \\
$55-64$ & 266 & 12.2 & 11.8 & \\
$\quad 65+$ & 277 & 10.6 & 16.5 & \\
Gender & & & & \\
Female & 1070 & 54.3 & 53.1 & \\
$\quad$ Male & 869 & 45.8 & 46.9 & \\
Race/ethnicity & & & & \\
Asian & 94 & 5.4 & 7.7 & \\
$\quad$ Black & 265 & 16.7 & 16.5 & \\
$\quad$ White & 1188 & 53.1 & 54.8 & \\
$\quad$ Hispanic & 293 & 20.6 & 18.5 & \\
$\quad$ Other & 67 & 4.2 & 2.6 & \\
\hline
\end{tabular}

the same." To assess social support at work, we asked respondents currently employed at follow-up if the level of understanding from their boss or coworkers increased after the September 11 attacks.

We identified cases of probable PTSD using a modified version of the National Women's Study (NWS) PTSD module ${ }^{20}$ based on the Diagnostic and Statistical Manual of Mental Disorders, third edition revised (DSM-III-R). ${ }^{21}$ This PTSD scale is designed for administration by trained, nonclinical interviewers and has been used in a number of large-scale mental health surveys. $^{8,22,23}$ The NWS PTSD scale includes questions on the three PTSD criteria domains: reexperiencing (B), avoidance (C), and arousal (D). Probable PTSD cases were required to have one symptom from criterion $\mathrm{B}$, three from criterion $\mathrm{C}$, and two from criterion D. To identify cases of probable PTSD related to the September 11 attacks, we required that all content-related symptoms be associated with the attacks. The Cronbach alpha for the symptoms used in this scale was $0.90 .^{24}$ In addition, when validated against the clinician-administered Structured Clinical Interview for Diagnostic and Statistical Manual of Mental Disorders, third edition revised $(S C I D),{ }^{25}$ the NWS PTSD scale had a sensitivity of $98.8 \%$ and a specificity of $79.1 \% .^{20}$ In a validation study comparing the NWS PTSD module with the PTSD Check List (PCL), ${ }^{26}$ an established screening measure for PTSD, the PCL had a sensitivity of $75 \%$ and a specificity of $95 \%$ in detecting PTSD cases as classified by our instrument. ${ }^{27,28}$ In a receiver operating characteristic analysis, ${ }^{29}$ we found that the optimal recommended PCL cutoff score of $\geq 50$ best predicted PTSD using our instrument (area under the curve $=$ 0.97). ${ }^{30}$ At baseline, we measured the prevalence of probable PTSD since September 11. At follow-up, we measured the prevalence of probable PTSD since baseline. Respondents with persistent probable PTSD met criteria at baseline and followup.

\section{Statistical Analyses}

Sampling weights were developed and applied to baseline data to correct for potential selection bias relating to the number of household telephones, persons in the household, and oversampling; sampling weights to correct for potential nonresponse bias were applied to the follow-up data. The prevalence of probable PTSD at baseline and follow-up was determined. We used 2-tailed chisquared tests to test for associations between the covariates of interest and the persistence of probable PTSD. Covariates that were significantly associated with the persistence of probable PTSD $(P \leq 0.10)$ were included in multivariable regression models. We developed three multivariable regression models for job loss and work-related (work stress and job satisfaction) predictors of PTSD persistence. Job loss and work-related predictors were studied in independent models because work-related predictors involved only currently employed respondents. Work stress and job satisfaction were studied in separate models. Factors hypothesized to be predictors of PTSD persistence (job loss as a result of September 11, unemployment at any time since baseline, work stress, and job satisfaction) were included in multivariable models irrespective of their levels of association in bivariate analyses. All analyses were performed using SUDAAN. ${ }^{31}$

\section{Results}

\section{Sample}

The demographic characteristics of the prospective sample are presented in Table 1. The age, gender, and race/ethnicity distributions of this sample were comparable to estimates from 2000 U.S. Census data, ${ }^{32}$ as well as to the baseline sample. The mean age was 42.5 years, $54.3 \%$ of respondents were female, and the racial/ethnic composition was $53.1 \%$ white, $16.7 \%$ black, $20.6 \%$ Hispanic, and 5.4\% Asian. Of the 1939 members of the cohort, 1224 persons were employed at follow-up.

At baseline, approximately six months after September 11, 149 persons met criteria for probable PTSD since and related to the September 11 attacks and were considered cases of probable PTSD. At follow-up, ap- 


\section{TABLE 2}

Bivariate Associations Between Job Loss and Work-Related Factors and the Persistence of Probable Posttraumatic Stress Disorder One Year After the September 11 Terrorist Attacks Among Residents of the New York City Metropolitan Area $(n=1939)$

\begin{tabular}{|c|c|c|c|c|c|}
\hline & \multicolumn{2}{|c|}{ PTSD at baseline } & \multicolumn{2}{|c|}{ PTSD at follow-up } & \multirow[b]{2}{*}{$P$ value } \\
\hline & No. & Percent & No. Persistent & Percent Persistent & \\
\hline Total & 149 & 100.00 & 64 & 42.7 & \\
\hline \multicolumn{6}{|c|}{ Lost job as a result of September 11} \\
\hline No & 134 & 87.7 & 57 & 40.2 & \multirow[t]{2}{*}{0.25} \\
\hline Yes & 15 & 12.3 & 7 & 64.6 & \\
\hline \multicolumn{6}{|l|}{ Income at baseline } \\
\hline$\$ 100,000+$ & 22 & 8.0 & 5 & 33.7 & \multirow[t]{8}{*}{0.001} \\
\hline$\$ 75,000-99,999$ & 11 & 8.4 & 1 & 0.5 & \\
\hline$\$ 50,000-74,999$ & 21 & 10.5 & 10 & 55.2 & \\
\hline$\$ 40,000-49,999$ & 8 & 9.1 & 4 & 44.5 & \\
\hline$\$ 30,000-39,999$ & 21 & 13.9 & 12 & 69.4 & \\
\hline$\$ 20,000-29,999$ & 14 & 10.6 & 5 & 34.9 & \\
\hline$<\$ 20,000$ & 33 & 25.8 & 21 & 46.9 & \\
\hline Missing & 22 & 13.6 & 8 & 44.1 & \\
\hline \multicolumn{6}{|c|}{ Unemployment at any time since baseline } \\
\hline No & 106 & 75.6 & 43 & 36.8 & \multirow[t]{2}{*}{0.03} \\
\hline Yes & 46 & 24.4 & 23 & 66.5 & \\
\hline \multicolumn{6}{|c|}{ Increase in income since baseline } \\
\hline No & 118 & 94.3 & 52 & 42.7 & \multirow[t]{2}{*}{0.95} \\
\hline Yes & 6 & 5.7 & 3 & 44.5 & \\
\hline \multicolumn{6}{|c|}{ Decrease in income since baseline } \\
\hline No & 109 & 85.8 & 47 & 39.6 & \multirow[t]{2}{*}{0.30} \\
\hline Yes & 15 & 14.2 & 8 & 62.3 & \\
\hline \multicolumn{6}{|l|}{ Work stress ${ }^{*}$} \\
\hline 1 (low) & 13 & 10.4 & 4 & 53.8 & \multirow[t]{5}{*}{0.002} \\
\hline 2 & 9 & 7.7 & 2 & 2.2 & \\
\hline 3 & 19 & 25.1 & 4 & 26.0 & \\
\hline 4 & 26 & 28.7 & 12 & 52.5 & \\
\hline 5 (high) & 20 & 28.1 & 12 & 55.6 & \\
\hline \multicolumn{6}{|l|}{ Work stress combined* } \\
\hline 1-3 (low) & 41 & 43.2 & 10 & 28.4 & \multirow[t]{2}{*}{0.10} \\
\hline $4-5$ (high) & 46 & 56.8 & 24 & 54.0 & \\
\hline \multicolumn{6}{|l|}{ Change in job satisfaction ${ }^{*}$} \\
\hline Better since September 11 & 12 & 13.7 & 4 & 52.0 & \multirow[t]{3}{*}{0.24} \\
\hline Same since September 11 & 47 & 53.3 & 13 & 31.1 & \\
\hline Worse since September 11 & 28 & 33.0 & 17 & 58.5 & \\
\hline \multicolumn{6}{|c|}{ Increased understanding from boss since September 11} \\
\hline No & 90 & 83.7 & 40 & 39.0 & \multirow[t]{2}{*}{0.53} \\
\hline Yes & 18 & 16.3 & 9 & 49.6 & \\
\hline \multicolumn{6}{|c|}{ Increased support from coworkers since September 11} \\
\hline No & 91 & 79.8 & 39 & 41.0 & \multirow[t]{2}{*}{0.87} \\
\hline Yes & 23 & 20.3 & 10 & 38.2 & \\
\hline
\end{tabular}

*These categories include responses from respondents employed at follow-up only.

PTSD, posttraumatic stress disorder.

proximately six months later, probable PTSD persisted in 64 , or $42.7 \%$, of the 149 cases of probable PTSD.

\section{Bivariate Analyses}

Table 2 shows the bivariate associations of job loss and work-related factors with the persistence of probable PTSD. Significant predictors of the persistence of probable PTSD were midrange income $(P=0.001)$, unemployment at any time since baseline $(P=0.03)$, and high levels of perceived work stress $(P=$ 0.002 ).

\section{Multivariable Analyses}

Results from multivariable models predicting associations between 1) employment status and the persis- tence of probable PTSD, 2) work stress and the persistence of probable PTSD, and 3) job satisfaction and the persistence of probable PTSD are presented in Tables 3, 4, and 5, respectively. In Table 3, the factors that predicted the persistence of probable PTSD after September 11 among all cohort members included unemployment at any time since the 


\section{TABLE 3}

Multivariable Model Predicting Associations Between Employment, Job Loss Factors, and the Persistence of Probable Posttraumatic Stress Disorder One Year After the September 11 Terrorist Attacks Among Residents of the New York City Metropolitan Area $(N=1939)$

\begin{tabular}{|c|c|c|c|}
\hline & Odds ratio & $95 \% \mathrm{Cl}$ & $P$ value \\
\hline \multicolumn{4}{|l|}{ Currently employed } \\
\hline No & 1.00 & & \\
\hline Yes & 1.07 & $(0.33-3.42)$ & 0.91 \\
\hline \multicolumn{4}{|c|}{ Lost job as a result of September 11} \\
\hline No & 1.00 & & \\
\hline Yes & 0.65 & $(0.13-3.25)$ & 0.60 \\
\hline \multicolumn{4}{|c|}{ Unemployed at any time since baseline } \\
\hline No & 1.00 & & \\
\hline Yes & 4.37 & $(1.22-15.73)$ & 0.02 \\
\hline \multicolumn{4}{|l|}{ Income at baseline } \\
\hline$\$ 100,000+$ & 1.00 & & \\
\hline$\$ 75,000-99,999$ & 0.01 & $(0.00-0.11)$ & $<0.001$ \\
\hline$\$ 50,000-74,999$ & 2.37 & $(0.27-21.00)$ & 0.44 \\
\hline$\$ 40,000-49,999$ & 1.34 & $(0.13-14.12)$ & 0.80 \\
\hline$\$ 30,000-39,999$ & 3.27 & $(0.43-24.69)$ & 0.25 \\
\hline$\$ 20,000-29,999$ & 0.64 & $(0.06-6.75)$ & 0.71 \\
\hline$<\$ 20,000$ & 1.42 & $(0.19-10.83)$ & 0.73 \\
\hline Missing & 0.90 & $(0.10-8.12)$ & 0.93 \\
\hline
\end{tabular}

$\mathrm{Cl}$, confidence interval.

\section{TABLE 4}

Multivariable Model Predicting Associations Between Work Stress, Job Loss, and the Persistence of Probable Posttraumatic Stress Disorder One Year After the September 11 Terrorist Attacks Among Currently Employed Residents of the New York City Metropolitan Area $(N=1224)$

\begin{tabular}{|c|c|c|c|}
\hline & Odds ratio & $95 \% \mathrm{Cl}$ & $\boldsymbol{P}$ value \\
\hline \multicolumn{4}{|l|}{ Work stress } \\
\hline Low (1-3) & 1.00 & & \\
\hline High (4-5) & 9.78 & $(1.52-62.97)$ & 0.02 \\
\hline \multicolumn{4}{|c|}{ Lost job as a result of September 11} \\
\hline No & 1.00 & & \\
\hline Yes & 0.89 & $(0.11-7.42)$ & 0.91 \\
\hline \multicolumn{4}{|c|}{ Unemployed at any time since baseline } \\
\hline No & 1.00 & & \\
\hline Yes & 10.97 & $(1.59-75.77)$ & 0.02 \\
\hline \multicolumn{4}{|l|}{ Income at baseline } \\
\hline$\$ 100,000+$ & 1.00 & & \\
\hline$\$ 75,000-99,999$ & 0.01 & $(0.00-0.17)$ & 0.002 \\
\hline$\$ 50,000-74,999$ & 3.49 & $(0.31-39.02)$ & 0.31 \\
\hline$\$ 40,000-49,999$ & 1.83 & $(0.10-34.08)$ & 0.69 \\
\hline$\$ 30,000-39,999$ & 2.58 & $(0.25-26.55)$ & 0.43 \\
\hline$\$ 20,000-29,999$ & 0.33 & $(0.02-7.18)$ & 0.48 \\
\hline$<\$ 20,000$ & 4.20 & $(0.38-47.00)$ & 0.24 \\
\hline Missing & 0.06 & $(0.00-2.75)$ & 0.15 \\
\hline
\end{tabular}

$\mathrm{Cl}$, confidence interval.

baseline interview (odds ratio [OR] $=4.37, P=0.02$ ), but not the loss of a job as a result of September 11 $(\mathrm{OR}=0.65, P=0.60)$. As shown in Table 4, predictors of the persistence of probable PTSD after September
11 among the employed included high levels of perceived work stress $(\mathrm{OR}=9.78, P=0.02)$ and unemployment at any time since baseline (OR $=10.97, P=0.02)$, but not the loss of a job as a result of September
$11(\mathrm{OR}=0.89, P=0.91)$. Table 5 shows that job satisfaction was not associated with the persistence of probable PTSD among the employed $(\mathrm{OR}=5.14, P=0.13)$; only unemployment at any time since baseline predicted the persistence of probable PTSD after September 11 (OR = 10.47, $P=0.02$ ).

\section{Discussion}

Using a representative sample of NYC metropolitan area residents, we found that 12 months after the September 11, 2001 attacks, probable PTSD persisted in $42.7 \%$ of persons who met criteria for probable PTSD 6 months after the attacks. Unemployment at any time during the follow-up period was a significant predictor of the persistence of probable PTSD among all cohort members and among cohort members employed at follow-up. High levels of perceived work stress, but not worse job satisfaction, predicted the persistence of probable PTSD among persons employed at follow-up.

\section{Unemployment}

We found that unemployment at any time during the follow-up period predicted the persistence of probable PTSD in our total sample. Our findings are consistent with those from prior studies that have assessed the correlates of mental health disorders among refugees and asylum seekers. ${ }^{16,18,33,34}$ These studies generally agree that unemployment in the postmigration/posttrauma recovery period is associated with the persistence of PTSD symptoms. Findings relating to the effects of reemployment on mental health have been inconclusive; although numerous studies have reported that reemployment has remedial effects on poor states of mental health, ${ }^{35,36}$ others have suggested that reemployment may actually worsen mental health status. ${ }^{37}$ In our study, we found that unemployment at any time since baseline was associated with a greater than 10-fold increase in the likelihood of persistent probable 


\section{TABLE 5}

Multivariable Model Predicting Associations Between Job Satisfaction, Job Loss Factors, and the Persistence of Probable Posttraumatic Stress Disorder Among Currently Employed Residents of the New York City Metropolitan Area $(N=1224)$

\begin{tabular}{|c|c|c|c|}
\hline & Odds ratio & $95 \% \mathrm{Cl}$ & $P$ value \\
\hline \multicolumn{4}{|l|}{ Work satisfaction } \\
\hline Better now & 0.77 & $(0.08-7.34)$ & 0.82 \\
\hline Stayed the same & 1.00 & & \\
\hline Worse now & 5.14 & $(0.61-43.06)$ & 0.13 \\
\hline \multicolumn{4}{|c|}{ Lost job as a result of September 11} \\
\hline No & 1.00 & & \\
\hline Yes & 0.29 & $(0.04-1.98)$ & 0.21 \\
\hline \multicolumn{4}{|c|}{ Unemployed at any time since baseline } \\
\hline No & 1.00 & & \\
\hline Yes & 10.47 & $(1.42-77.13)$ & 0.02 \\
\hline \multicolumn{4}{|l|}{ Income at baseline } \\
\hline$\$ 100,000+$ & 1.00 & & \\
\hline$\$ 75,000-99,999$ & 0.01 & $(0.00-0.13)$ & 0.001 \\
\hline$\$ 50,000-74,999$ & 1.22 & $(0.13-11.14)$ & 0.86 \\
\hline$\$ 40,000-49,999$ & 0.49 & $(0.05-4.81)$ & 0.54 \\
\hline$\$ 30,000-39,999$ & 2.66 & $(0.24-29.41)$ & 0.43 \\
\hline$\$ 20,000-29,999$ & 0.16 & $(0.00-8.50)$ & 0.37 \\
\hline$<\$ 20,000$ & 3.00 & $(0.23-39.00)$ & 0.40 \\
\hline Missing & 0.03 & $(0.00-1.71)$ & 0.09 \\
\hline
\end{tabular}

$\mathrm{Cl}$, confidence interval.

PTSD among those employed at 12 months, suggesting that the remedial effect of reemployment in our sample was not substantial.

Although we found that unemployment between 6 and 12 months after September 11 predicted the persistence of probable PTSD, persons who experienced job loss as a result of September 11 in the first 6 months after September 11 were not more likely to satisfy criteria for persistent probable PTSD. There are 2 plausible explanations for these disparate results. First, it is possible that job loss in the first 6 months did not predict the persistence of probable PTSD at 12 months because the negative effects of job loss on recovery from probable PTSD may be shortlived. Second, the lack of association observed between job loss as a result of September 11 and the persistence of probable PTSD may be explained by the nature of the job loss itself. It is possible that persons who lost a job directly as a result of the September 11 attacks felt less personally accountable for their job loss and consequently suffered relatively fewer negative psychologic effects. This explanation has been supported by literature that shows that job terminations often result in disparate mental health effects. ${ }^{38}$

\section{Work Stress and Job Satisfaction}

An association between work stress and symptoms of posttraumatic stress has been established in occupational studies of police officers and firefighters, ${ }^{13,14}$ and an association between job strain and poor mental health has also been shown among women in a general population survey. ${ }^{39}$ Among persons employed 12 months after September 11, we found that those with high levels of perceived work stress were almost 10 times as likely as those with low levels of work stress to satisfy criteria for probable PTSD, suggesting an association between high levels of perceived work stress and the persistence of probable PTSD. However, inference relating to the causality of this association is limited; although our findings sug- gest that high levels of work stress hinder recovery from negative mental health symptoms, it is also possible that this association is explained by a common risk factor. For instance, poor coping strategies, which have been associated with increased levels of perceived work stress ${ }^{14,40}$ and the persistence of PTSD, ${ }^{41,42}$ may have served as a common risk factor for both maladies.

We found that persons who described their satisfaction with work 12 months after September 11 as "worse now than before September 11 " were no more likely than persons whose job satisfaction remained the same to satisfy criteria for persistent probable PTSD. Our results are contrary to those of previous studies. ${ }^{12,41,43}$ For instance, a study of rescue workers after the Oklahoma City bombing reported that PTSD was associated with reduced job satisfaction. ${ }^{44}$ The lack of agreement between these results and ours may be attributable to the moderating effects of job insecurity on the job satisfaction/PTSD relation. There are two possible explanations that support this hypothesis. First, as suggested by Turner, workers may simply be happy to have a job during periods of high unemployment. ${ }^{45}$ Thus, in the aftermath of the September 11 attacks, when unemployment rates were high, job satisfaction may not have been associated with mental health outcomes. Second, during periods of elevated job insecurity, PTSD may actually be associated with high, as opposed to low, levels of job satisfaction, conceivably because persons more satisfied with their work value their jobs more highly and are more afraid of potential job loss. ${ }^{46}$ For example, in a study of public sector employees experiencing workplace organization, Probst found that individuals with high levels of job satisfaction experienced higher levels of psychologic distress when job insecurity was an issue. $^{46}$ 


\section{Limitations}

There are several limitations to this study. First, we used telephone interviews to identify cases of probable PTSD. Although it has been shown that telephone and in-person assessment of DSM-III Axis I disorders, including anxiety disorders and affective disorders, result in comparable estimates of symptomatolo$\mathrm{gy},{ }^{47}$ PTSD assessed in this manner cannot be equated to a full diagnosis of PTSD, and comparisons between the results of this study and others should be made prudently. Second, although our measures of work stress and job satisfaction represented salient markers from well-defined and characterized scales, they were limited to only a few items and thus may not have conclusively defined these psychosocial constructs. Third, we did not include measures of social support in our analyses. Although the purpose of this study was to assess the relation between unemployment and adverse working conditions on the persistence of probable PTSD, it is possible that levels of social support influence this association. Fourth, we were unable to complete follow-up interviews for $29 \%$ of baseline respondents. Although our follow-up group was comparable to our baseline sample, it is possible that persons with more severe symptoms of PTSD were differentially lost to follow-up. Fifth, our findings relating to the effects of unemployment on the persistence of PTSD must be interpreted with caution. Our cohort study design assessed unemployment and PTSD at 6-month intervals and did not establish with certainty the temporality between an instance of unemployment and the presence of PTSD symptoms. Because of this, a person whose PTSD symptoms were fully resolved 7 months after September 11 but who subsequently lost a job 8 months after September 11 would be classified as a person with persistent probable PTSD who was unemployed at any time since baseline, creating a spurious association between unemployment and the perpetuation of PTSD symptoms. However, because the number of these cases is probably small, this limitation is not likely to explain the association observed between unemployment at any time since baseline and the persistence of probable PTSD. Similarly, it is difficult to establish temporality between times of high levels of stress perception and the presence of PTSD symptoms. Although our findings are consistent with most peer-reviewed work in the area, it is possible that PTSD symptoms influence levels of perceived work stress. Finally, it is possible that mental health status influenced the movement of persons into and out of unemployment, thus affecting the association between unemployment and mental health. However, prior studies have demonstrated that this type of effect is least pronounced when employment prospects are unfavorable, ${ }^{45}$ as was the case after September 11.

\section{Conclusions}

Our findings suggest that unemployment and exposure to adverse work conditions, particularly high levels of perceived work stress, may be important determinants of the persistence of posttraumatic stress after a disaster. We found that reemployment did not result in the rapid resolution of posttraumatic stress symptoms and that decreased work satisfaction was not associated with the persistence of PTSD. Future studies should establish temporality between traumatic events, instances of unemployment, perceived job stress, and posttraumatic symptomatology and consider the effect of job security in the regional economy. Furthermore, research should begin to assess the impact of specific characteristics of the work environment such as the industry, the type of work, the social connectedness of the work environment, and the amount of available support resources on the persistence of psychologic symptoms after a disaster. This informa- tion can identify specific job-related conditions associated with postdisaster recovery and guide policy.

\section{Acknowledgment}

This work was supported by the National Institute on Drug Abuse (DA14219-01S1), and the National Institute of Mental Health (MH66081-01; MH66391-01).

\section{References}

1. New York City Office of the Comptroller. One year later: The fiscal impact of 9/11 on New York City. September 4, 2002. Available at: http://www.comptroller.nyc.gov/bureaus/bud/reports/impact9-11-year-later.pdf. Accessed June 24, 2003.

2. Fiscal Policy Institute. The employment impact of the September 11 World Trade Center attacks: updated estimates based on the benchmarked employment data. March 8, 2002. Available at: http:// www.fiscalpolicy.org/Employment\% 20Impact \%20of\%20September\%2011 Update.pdf. Accessed June 24, 2003.

3. New York State Department of Labor. Local area unemployment statistics. Available at: http://64.106.160.140:8080/ $1 \mathrm{mi} /$ laus results.jsp?PASS $=1 \&$ area $=$ $10000007 \mathrm{New}+$ York + City + Region. Accessed June 24, 2003.

4. DeLisi LE, Mauricio A, Yost M, et al. A survey of New Yorkers after the Sept. 11, 2001 terrorist attacks. Am J Psychiatry. 2003;160:780-783.

5. Fiscal Policy Institute. World Trade Center job impacts take a heavy toll on low-wage labor. November 5, 2001. Available at: http://www.fiscalpolicy.org/Nov5WTCreport.PDF. Accessed June 24, 2003.

6. CBS News. New York City: one year later. September 11, 2002. Available at: http://www.cbsnews.com/stories/2002/ 09/16/opinion/polls/main522070.shtml. Accessed June 9, 2003.

7. Galea S, Ahern J, Resnick $\mathrm{H}$, et al. Psychological sequelae of the September 11 terrorist attacks in New York City. N Engl J Med. 2002;346:982-987.

8. Galea S, Vlahov D, Resnick $H$, et al. Trends in probable posttraumatic stress disorder in New York City after the September 11 terrorist attacks. Am J Epidemiol. 2003;158:514-524.

9. Rahmqvist M, Carstensen J. Trend in psychological distress in a Swedish population from 1989 to 1995. Scand J Soc Med. 1998;26:214-222.

10. Tausig M, Fenwick R. Recession and 
well-being. J Health Soc Behav. 1999;40: 1-16.

11. Karasek RA, Theorell T. Healthy WorkStress, Productivity, and the Reconstruction of Working Life. New York: Basic Books; 1990.

12. Carlier I, Lamberts RD, Gersons B, et al. Risk factors for posttraumatic stress symptomatology in police officers: a prospective analysis. J Nerv Ment Dis. 1997; 185:498-506.

13. Corneil W, Beaton R, Murphy S, et al. Exposure to traumatic incidents and prevalence of posttraumatic stress symptomatology in urban firefighters in two countries. J Occup Health Psychol. 1999;4: 131-141.

14. Gershon R, Lin S, Li X. Work stress in aging police officers. $J$ Occup Environ Med. 2002;44:160-167.

15. Jones L, Hughes M, Unterstaller U. Posttraumatic stress disorder (PTSD) in victims of domestic violence: a review of the research. Trauma Violence Abuse. 2001; 2:99-119.

16. Lie B. A 3-year follow-up study of psychosocial functioning and general symptoms in settled refugees. Acta Psychiatr Scand. 2002;106:415-425.

17. van der Ploeg E, Dorresteijn SM, Kleber RJ. Critical incidents and chronic stressors at work: their impact on forensic doctors. J Occup Health Psychol. 2003; 8:157-166

18. Silove D, Steel Z, Watters C. Policies of deterrence and the mental health of asylum seekers. JAMA. 2000;284:604-611.

19. Hull AM, Alexander DA, Klein S. Survivors of the Piper Alpha oil platform disaster: long-term follow-up study. $\mathrm{Br} \mathrm{J}$ Psychiatry. 2002;181:433-438.

20. Kilpatrick DG, Resnick HS, Freedy JR, et al. The posttraumatic stress disorder field trial: evaluation of the PTSD construct-criteria A through E. In: Widiger TA, Frances AJ, Pincus HA, et al., eds. DSM-IV Sourcebook, vol 4. Washington, DC: American Psychiatric Association Press; 1998:803-844.

21. American Psychiatric Association. Diagnostic and Statistical Manual of Mental Disorders, 3rd ed., revised. Washington, DC: American Psychiatric Association; 1987.

22. Acierno R, Kilpatrick DG, Resnick H, et al. Assault, PTSD, family substance use, and depression as risk factors for cigarette use in youth: findings from the National Survey of Adolescents. J Trauma Stress. 2000;13:381-396.

23. Resnick HS, Kilpatrick DG, Dansky BS, et al. Prevalence of civilian trauma and posttraumatic stress disorder in a representative national survey of women. J Consult Clin Psychol. 1993;61:984-991.

24. Galea S, Boscarino J, Resnick H, et al. Mental health in New York City after the September 11 terrorist attacks: results from two population surveys. In: Manderscheid RW, Henderson MJ, eds. Mental Health, United States 2002. Washington DC: Government Printing Office. In press.

25. Spitzer RL, Williams JB, Gibbon M. Structured Clinical Interview for DSMIII-R-Non-patient Version. New York: Biometrics Research Department, New York State Psychiatric Institute; 1987.

26. Blanchard EB, Jones-Alexander J, Buckley TC, et al. Psychometric properties of the PTSD checklist (PCL). Behav Res Ther. 1996;34:669-673.

27. Boscarino JA, Galea S, Ahern J, et al. Psychiatric medication use among Manhattan residents following the World Trade Center Disaster. J Trauma Stress. 2003;16:301-306.

28. Galea S, Resnick H, Kilpatrick D, et al. Epidemiology of post-traumatic stress disorder in the general population after the September 11 attacks. PTSD Quarterly. 2004;15:1-7.

29. Hosmer DW, Lemeshow S. Applied Logistic Regression. New York: John Wiley \& Sons; 2000.

30. Boscarino JA, Galea S, Adams RE, et al. Mental health service and medication use in New York City after the September 11, 2001, terrorist attack. Psychiatr Serv. 2004;55:1-10.

31. Shah B, Barnwell B, Bieler G. SUDAAN User's Manual, release 7.5. Research Triangle Park, NC: Research Triangle Institute; 1997.

32. Bureau of the Census. 2000 Census Report. Washington, DC: US Department of Commerce; 2000.

33. Hermansson A, Timpka T, Thyberg M. The mental health of war-wounded refugees: an 8-year follow-up. J Nerv Ment Dis. 2002;190:374-380.

34. Kivling-Boden G, Sundbom E. The rela- tionship between post-traumatic symptoms and life in exile in a clinical group of refugees from the former Yugoslavia. Acta Psychiatr Scand. 2002;105:461468.

35. Kessler RC, House JS, Turner JB. Unemployment and health in a community sample. J Health Soc Behav. 1987;28:5159.

36. Warr PB, Jackson P, Banks M. Unemployment and mental health: some British studies. J Soc Issues. 1988;44:47-68.

37. Dooley D, Catalano R, Rook KS. Personal and aggregate unemployment and psychological symptoms. J Soc Issues. 1988;44:107-123.

38. Jahoda M. Employment and Unemployment. Cambridge: Cambridge University Press; 1982.

39. Bildt C, Michelsen H. Gender differences in the effects from working conditions on mental health: a 4-year follow-up. Int Arch Occup Environ Health. 2002;75: 252-258.

40. Tyler P, Cushway D. Stress, coping, and mental well-being in hospital nurses. Stress Med. 1992;8:91-98.

41. North CS, McCutcheon V, Spitznagel EL, et al. Three year follow-up of survivors of a mass shooting episode. J Urban Health. 2002;79:383-391.

42. Sutker PB, Davis JM, Uddo M, et al. War zone stress, personal resources, and PTSD in Persian Gulf War returnees. J Abnorm Psychol. 1995;104:444-452.

43. Abramson JH, Gofin J, Habib J, et al. Work satisfaction and health in the middle-aged and elderly. Int $J$ Epidemiol. 1994;23:98-106.

44. North CS, Tivis L, McMillen JC, et al. Coping, functioning, and adjustment of rescue workers after the Oklahoma City bombing. J Trauma Stress. 2003;15:171175.

45. Turner JB. Economic context and the health effects of unemployment. J Health Soc Behav. 1995;36:213-229.

46. Probst TM. Wedded to the job: moderating effects of job involvement on the consequences of job insecurity. J Occup Health Psychol. 2000;5:63-73.

47. Paulsen AS, Crowe RR, Noyes R, et al. Reliability of the telephone interview in diagnosing anxiety disorders. Arch Gen Psychiatry. 1988;45:62-63. 